\title{
Erratum to: Recovery of butanol from model ABE fermentation broths using MFI adsorbent: a comparison between traditional beads and a structured adsorbent in the form of a film
}

\author{
Abrar Faisal $^{1} \cdot$ Ming Zhou $^{1} \cdot$ Jonas Hedlund $^{1} \cdot$ Mattias Grahn $^{1}$
}

Published online: 29 February 2016

(C) Springer Science+Business Media New York 2016

\section{Erratum to: Adsorption (2016) 22:205-214 DOI 10.1007/s10450-016-9759-z}

Authors regret that in the above-mentioned recently published article a reference was wrongly cited.

Reference "Farzaneh, A., Richards, T., Sklavounos, E., van Heiningen, A.: A kinetic study of $\mathrm{CO}_{2}$ and steam gasification of char from lignin produced in the SEW process. BioResources 9(2), 3052-3063 (2014)" should have read: Farzaneh, A., Zhou, M., Potapova, E., Bacsik, Z., Ohlin, L., Holmgren, A., Hedlund, J., Grahn, M.: Adsorption of water and butanol in silicalite-1 film studied with in-situ attenuated total reflectance-Fourier transform infrared spectroscopy. Langmuir 31(17), 4887-4894 (2015)".

The authors would like to apologize for any inconvenience caused.

The online version of the original article can be found under doi:10.1007/s10450-016-9759-z.

Abrar Faisal

abrar.faisal@1tu.se

1 Chemical Technology, Luleå University of Technology,

97187 Luleå, Sweden 